\title{
Skyscapes of the Mesolithic/Neolithic Transition in Western England
}

\section{Pamela Armstrong}

\begin{abstract}
:
This paper explores the skyscapes of central southern England during the Mesolithic/Neolithic transition. It suggests that those who built the structures known as the Cotswold-Severn tombs embedded architectural details within their monuments that linked to celestial horizon events for both navigational and calendrical purposes. The architectural designs found within the tombs are analysed for evidence of a cultural engagement with landscape archaeology and the sky. This period witnessed a transition between two eras, so this research considers the possibility that there may also have been a shift in the type of skywatching practised by those inhabiting this landscape during this time of change.
\end{abstract}

\section{Introduction}

The question considered for this paper was, 'Does the archaeoastronomic record of the Cotswold-Severn region reflect evidence of a transition from lunar to solar alignment?' The monuments surveyed for this research were Neolithic Cotswold Severn long barrows, much like the one below, known as Crippets (Fig. 1). These are earthen mounds which have been described by Kinnes as 'the finest group of stone chambered tombs in England'. ${ }^{1}$

North defines a barrow as 'a mound, deliberately erected out of earth and other material [...] and having a conscious architectural structure. Usually, but not always, built for burial purposes'. ${ }^{2}$ Darvill estimates that there are about 500 long barrows in Britain. ${ }^{3}$ The Cotswold Severn tombs

\footnotetext{
${ }^{1}$ I. Kinnes, R. J. Mercer, and I. F. Smith, 'Research Priorities in the British Neolithic' (unpublished report submitted to the DoE by the Prehistoric Society, 1976), p. 6.

2 John North, Stonehenge Neolithic Man and Cosmos (London: Harper Collins, 1997), p. xxiii.

3 Timothy Darvill, Long Barrows of the Cotswolds and Surrounding Areas (Brimscombe: Gloucestershire 2004), p. 71.
}

Pamela Armstrong, 'Skyscapes of the Mesolithic/Neolithic Transition in Western England', Culture and Cosmos, Vol. 17, no. 2, Autumn/Fall 2013, pp. 25-58. www.CultureAndCosmos.org 
began to appear on the southern English landscape at the onset of the fourth millennium BCE and currently about 200 barrows have been recorded in the region. ${ }^{4}$

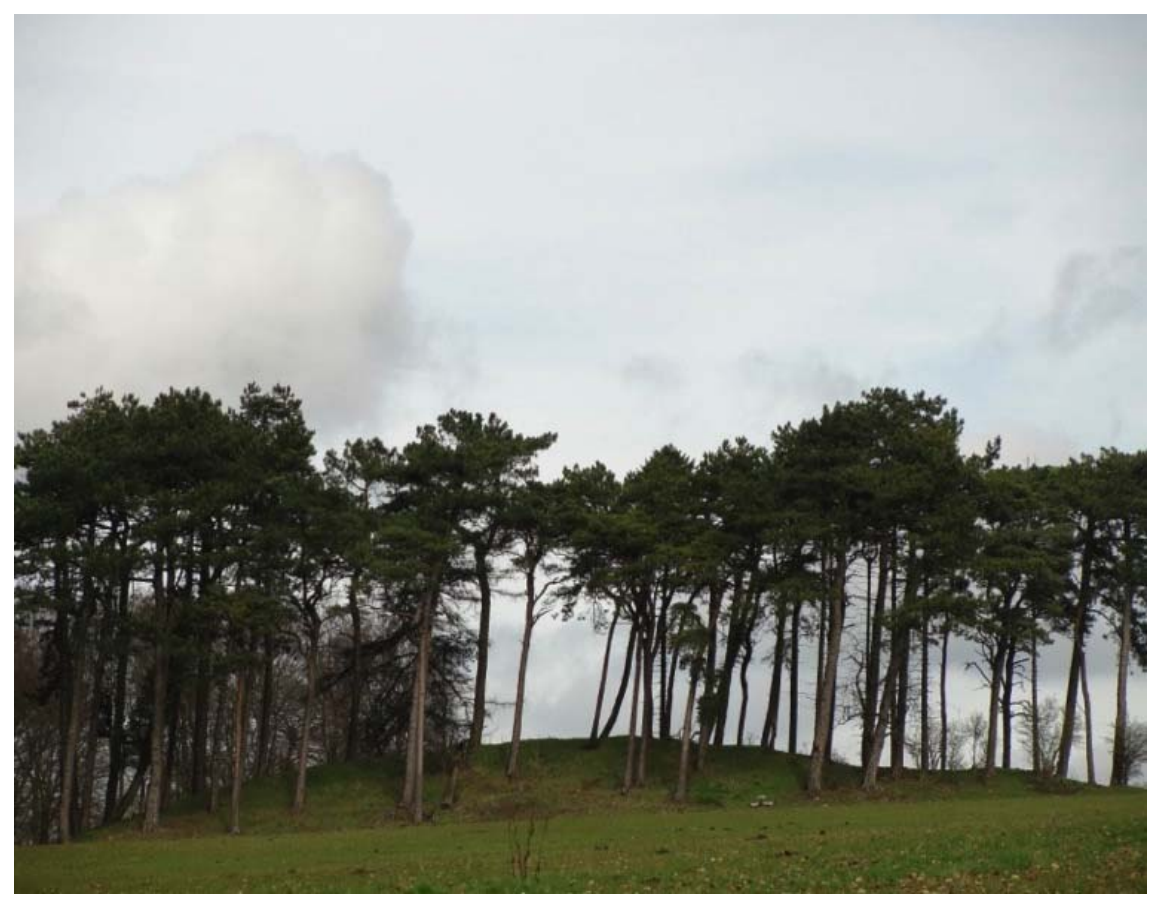

Fig. 1. Crippets long barrow. Cotswold escarpment. Gloucestershire UK. Author's photo.

The idea for my research grew from Sims' suggestion that Stonehenge is a Neolithic monument designed by those who built it to 'juxtapose, replicate and reverse' key horizon properties displayed by the sun and moon, apparently in order to invest the sun with the moon's former religious significance. ${ }^{5}$ He describes this process as 'solarization'. ${ }^{6}$ Sims argues that prior to the shift to pastoralism at the beginning of the Neolithic, there was a greater cultural engagement with lunar rather than solar astronomy. Sims suggests that pre-Neolithic communities organised themselves by 'phase-

\footnotetext{
${ }^{4}$ Darvill, Cotswolds, p. 83.

${ }^{5}$ Lionel Sims, 'The 'Solarization' of the Moon: Manipulated Knowledge at Stonehenge', Cambridge Archaeological Journal 16, no. 2 (2006): p. 1.

${ }^{6}$ Sims, 'Solarization', p. 2.

Culture and Cosmos
} 
locking their economic and ritual routines to the rhythms of the Moon'? He claims that Stonehenge's sarsen stone circle was used to 'modify and transcend' a lunar allegiance by superseding it with a solar one. ${ }^{8}$ Thus it was, in his view, a mechanism for engineering social change. It was essentially a binary monument, structurally designed to facilitate a symbolic transposition from the moon to the sun. Sims suggests his hypothesis be tested by investigating the region surrounding Stonehenge, which my research endeavoured to do. Most specifically I was exploring whether it is possible to identify a continuity or discontinuity of astronomic allegiance to luminaries across the Mesolithic to Neolithic transition.

A literature review quickly establishes that the barrows have a singular feature, and that is simply their massive bulk. The tombs were new to the landscape. Thomas describes them as 'perhaps the most archaeologically conspicuous element of the British Neolithic'. Indeed they mark the onset of this period, Darvill suggesting the new use of megaliths indicated 'a step-change' in construction and design. ${ }^{9}$ As DeMarrais points out:

Monuments can be impressive, even overwhelming constructions that are experienced simultaneously by a large audience. They are an effective and enduring means of communication, often expressing relatively unambiguous messages of power. ${ }^{10}$

Scarre argues that by building such monuments, the earliest Neolithic communities 'established a pattern of behaviour that set them apart from their Mesolithic antecedents'. ${ }^{11}$ So the earthen long barrows were radical in appearance, but there is debate about who built them. When Thomas writes of the social complexity of the 'Neolithic transition' he describes the phrase itself as 'protean'. ${ }^{12}$ In his view, it is a term with meanings ranging from:

\footnotetext{
7 Sims, 'Solarization', p. 3.

${ }^{8}$ Sims, 'Solarization'.

${ }^{9}$ Darvill, Cotswolds, p. 71.

${ }^{10}$ E. DeMarrais, L. J. Castillo, and T. Earle, 'Ideology, Materialization, and Power Strategies', Current Anthropology 37 (1996): p. 18.

${ }^{11}$ Chris Scarre, 'Changing Places: Monuments and the Neolithic Transition in Western France', in Going Over: The Mesolithic-Neolithic Transition in NorthWest Europe, eds. A. Whittle and V. Cummings (Oxford: Oxford University Press, 2002), p. 243.

12 Julian Thomas, The Birth of Neolithic Britain (Oxford: Oxford University Press, 2013), p. 1.
} 
a particular type of subsistence economy, a level of technological development, a chronological interval, a specific set of cultural entities, to racial or ethnic identities, or to a specific type of society. ${ }^{13}$

A significant feature of the shift from the Mesolithic was the move from a predominantly forager way of life to a generally agrarian one.

In some places the Mesolithic to Neolithic transition appeared to spread gradually across a region, while in other places it is sudden. RowleyConwy contends that the appearance of agriculture was 'not a demic "wave of advance" but rather a rapid and massive socioeconomic "wave of disruption". ${ }^{14}$ If he is correct, then monument building and its associated belief systems may have been in response to the tensions caused by that 'disruption'. So these monuments emerged at a time of great change though there can only be speculation as to whether the ideologies associated with them reflected or indeed shaped inherent societal shifts. If they contained features to do with astronomy in particular, then this astronomy was either new to the landscape or it was being embedded in the material culture in a new way. Ruggles suggests this can be a process which generates tension, writing:

discontinuities of ritual tradition, as manifested by clear changes in the patterns of astronomical symbolism incorporated in public monuments, may indicate significant social upheaval. ${ }^{15}$

This would support Thomas' view that the barrow builders had new and pressing economic imperatives. He writes:

People do not bury themselves: the burial of the dead is an aspect of the power strategies of the living. These new burial traditions were a means by which the inheritance of land and wealth from one individual to another was made legitimate. ${ }^{16}$

\footnotetext{
${ }^{13}$ Thomas, The Birth of Neolithic Britain.

14 Peter Rowley-Conwy, 'How the West Was Lost. A Reconsideration of Agricultural Origins in Britain, Ireland, and Southern Scandinavia', Current Anthropology 45 (2004): p. 97.

${ }^{15}$ Clive Ruggles, Astronomy in Prehistoric Britain and Ireland (New Haven: Yale University Press, 1999), p. 152.

${ }^{16}$ Julian Thomas, 'Relations of Production and Social Change in the Neolithic of North-West Europe', Royal Anthropological Institute of Great Britain and Ireland 22, no. 3 (1987): p. 423.
}

Culture and Cosmos 
Thus the Cotswold Severn earthen tombs may have functioned as a statement of intent, built to establish lineage and ownership in what was possibly a contested environment.

On the other hand it is possible there were regions where the transition did not precipitate upheaval, in which case monuments may have fulfilled altogether different functions. Silva and Franklyn point out that when divergent populations interact such as may have occurred between Mesolithic and Neolithic peoples, it is possible for transformation to occur rather than conflict. When considering belief systems for instance, they suggest that different communities each could act on each other, creating 'syncretic cosmologies with elements from both the colonised and coloniser's world-views' ${ }^{17}$ Thus, the emergence of the barrows in western England may have fulfilled a complex and not necessarily uniform suite of needs. What is known is that they were usually places of burial and thus memorial. Rowley-Conwy suggests they were monuments which constituted:

a durable focus for a community, enhanced by the physical presence of one or more founding ancestors who served to emphasize continuity with the collective past. ${ }^{18}$

But Thomas points out that even burial, a defining task universal to humanity, differed after the transition into the Neolithic. The people of the Mesolithic did not build enduring tombs, whereas in the Neolithic, he argues, monument building became 'a social strategy, which had the effect of bringing people together to labour and to engage in ritual observances'. ${ }^{19}$ The very act of monument construction, he suggests, was a communally cohering event. Thus a monument was a public statement, imbued with social meaning.

In the case of the earthen tombs they may have been intended not just as markers establishing territorial boundaries, but may have been used to enshrine shared cosmologies. Ruggles agrees that the tombs manifested a social and political complexity. But he is amongst those who also suggest

${ }^{17}$ Fabio Silva and Roslyn M. Frank, 'Deconstructing the Neolithic Myth: The Implications of Continuity for European Late Prehistory', Anthropological Notebooks 19, no. Supplement (2013): p. 232.

18 Thomas, Neolithic Britain, p. 92.

19 Julian Thomas, 'Thoughts on The "Repacked” Neolithic Revolution', Antiquity 77 (2003): p. 72. 
they had astronomic features. He says of the barrows that their 'orientation was certainly important'. ${ }^{20} \mathrm{He}$ also writes:

Perhaps, in small communities, astronomical alignments simply helped to affirm a monument as being at 'the centre of the world', but in other cases they may have had more to do with making its power impossible to challenge thereby affirming ideological structures and political control. ${ }^{21}$

As DeMarrais points out, the design of a structure is 'a means through which symbols, their meanings and beliefs can be manipulated to become an important source of social power'. ${ }^{22}$ Whatever the function of the barrows, whether they were built by indigenous Mesolithic huntergatherers, incoming Neolithic farmers or by selective appropriation between the two, this new architecture heralded the end of the Mesolithic in western England, and it may have contained astronomic intent. When a culture embeds the astronomy it practices within the fabric of a new structure, it is a declarative act inferring that continuity will apply. For those who are establishing territorial or ideological boundaries, an intended alignment from a power base - such as a barrow — to a celestial event links past, present and, critically, the future.

The methodology used in this research was shaped in part by the limited material record available. As Whittle points out, 'only three Cotswold long barrows or cairns have been more or less fully excavated'. ${ }^{23}$ Because of this I decided on a case study approach which focused on the three barrows Whittle specifically nominates. These were Burn Ground, Ascott-underWychwood and Hazleton North (Fig. 2). ${ }^{24}$

The value of a case study approach is that, as Stake suggests, it gives the researcher the opportunity to get to know each case 'extensively and intensively'. ${ }^{25}$ The case study approach is qualitative, and differs from quantitative research because, argues Stake, it 'seeks out a relationship

\footnotetext{
${ }^{20}$ Ruggles, Astronomy in Prehistoric Britain and Ireland, p. 125.

${ }^{21}$ Ruggles, Astronomy in Prehistoric Britain and Ireland, p. 154.

${ }^{22}$ DeMarrais, 'Power', p. 31.

23 Alasdair Whittle and Don Benson, 'Place and Time: Building and Remembrance', in Building Memories the Neolithic Cotswold Long Barrow at Ascott-under-Wychwood, Oxfordshire (Oxford: Oxbow, 2007), p. 327.

${ }^{24}$ Benson, 'Building and Remembrance', p. 327.

${ }^{25}$ Robert E. Stake, The Nature of Qualitative Research (London: Routledge, 1995), p. 36.
}

Culture and Cosmos 
between a small number of variables' ${ }^{26}$ Quantitative research looks for patterns amongst a large number of research objects. It is reductive and therefore difficult to apply to the Cotswold-Severn barrows, whose designs are complex and varied. Each barrow is different. Though there may be broad commonalities, no one design is commensurate with another, and it is impossible to reduce their architectural features to a manageably small set of significant markers. As Timothy Darvill explains, the barrows are monuments that display 'very considerable heterogeneity'. ${ }^{27}$ A quantitative approach militates against assessing the varied details particular to each barrow so because of this, a qualitative approach was chosen.

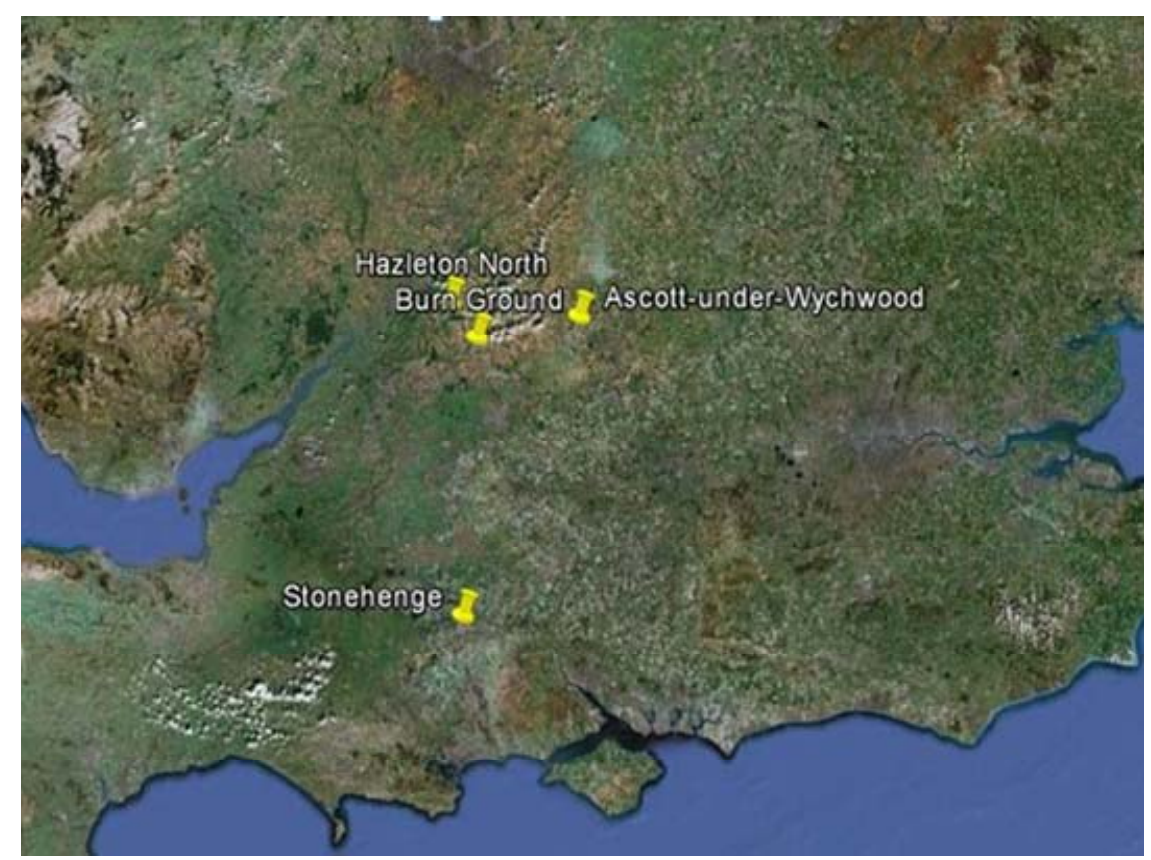

Fig. 2. Barrows’ North Cotswold location. Google earth image.

When I mentioned the three barrows above I used the past tense. The reason for this is that the very process of full excavation completely destroyed them. This total lack of material record has led to a reconsideration of what, in relation to this study, constitute primary and

${ }^{26}$ Stake, The Nature of Qualitative Research, p. 41.

${ }^{27}$ Darvill, Cotswolds, p. 44. 
secondary sources. Given Benson's confident assessment of the archaeological reports which record and describe the three excavations, I made those documents my primary material. ${ }^{28}$ Thus my primary sources became not the barrows themselves, but the reports associated with them.

The second reason that I chose to focus on these reports was because they provided dependable dates. This dating process allowed for the establishment of a time frame within which to compare and contrast each barrow. Burn Ground was built possibly at the end of the fifth millennium, around 4230-3970 cal BCE. ${ }^{29}$ Ascott-under-Wychwood was built just after the beginning of the fourth millennium, around 3760-3700 cal BCE. ${ }^{30}$ Hazleton North followed immediately, around 3710-3655 cal BCE. ${ }^{31}$ Thus these tombs predate Sarsen Stonehenge and, if it occurred, the 'solarization' period, by anything up to 1,500 years. ${ }^{32}$

Given the above, my methodology became a hybrid one which included the combined use of archaeological reports, maps and illustrations. Fieldwork calculations, phenomenological notes and a discussion of the horizon issues local to each site were also included. The calculations I arrived at combined fieldwork and map work. Modern features such as roads were used as key structures. I would locate the road nearest to a barrow and go into the field and measure its azimuth. I then used maps and archaeological plans to draw the angle between the road and the barrow. A protractor was used to calculate the difference. This hybrid approach was more dependable, the more precise the maps and illustrations. It was a methodology which had its limitations and was less reliable when a badly, or roughly drawn diagram was used. This deductive process, and the declinations which result from it, are fully discussed in my end summary.

The tools used for field work included a Garmin GPS 12 XL position finder, as well as a Suunto compass. A Suunto clinometer was used to measure horizon altitude. Magnetic anomalies were checked for at the

\footnotetext{
${ }^{28}$ Benson, 'Building and Remembrance', p. 327.

${ }^{29}$ Martin Smith and Megan Brickley, 'The Date And Sequence Of Use Of Neolithic Funerary Monuments: New A.M.S. Dating Evidence From the Cotswold - Severn Region', Oxford Journal of Archaeology 25, no. 4 (2006): p. 339.

${ }^{30}$ Alex Bayliss et al., 'One Thing after Another: The Date of the Ascott-underWychwood Long Barrow', Cambridge Archaeological Journal 17, no. 1 (suppl.) (2007): p. 29.

${ }^{31}$ J. Meadows, A. Barclay, and A. Bayliss, 'A short passage of time: Dating of the Hazleton Long Cairn Revisited’,Cambrdige Archaeological Journal 17 (S1) (2007) p. 54.

${ }^{32}$ Sims, 'Solarization', p. 2.

Culture and Cosmos
} 
location of all three excavations. Photographs and archaeological diagrams were used to infer the barrow's location as best possible. When checking for magnetic anomalies, two poles were inserted into the ground along the most probable orientation for each barrow and a compass was used to check the azimuth in each direction. None were found. True North was recalculated from Magnetic North by accessing the National Geophysical Data Centre's website. ${ }^{33}$ As this research used secondary sources to impute primary source measurements, all calculations would benefit from some leeway, thus an error margin of up to $2^{\circ}$ has been used throughout.

Though my study focused on the sun and the moon, I routinely checked for stellar orientation. Thus I noted Schaefer's discussion about the 'uncertainty' of a star's extinction angle, that is, the lowest point on the horizon at which it is visible. ${ }^{34}$ Two astronomy programmes were used: the first was Stellarium, and the second was Starlight, whose star catalogue I accessed. $^{35}$ Starlight's catalogue is compiled from the Yale Bright Star Catalogue and Ptolemy's Almagest. I have restricted stars chosen to those of a visual magnitude of 3 or less. All horizons east, west, north and south were assessed for celestial events.

The remit of this research was to search for orientations from the barrows to celestial horizon events and then to judge whether these indicated a shift from a lunar to solar allegiance over time. The hybrid methodology just described allowed me to establish a diachronic profile of one small part of the material record of the Mesolithic to Neolithic transition on the landscape just north of Stonehenge.

Earthen barrows contain both internal and external architectural features, and orientation can be measured from both. In general, barrows fulfilled a mortuary function, earthen mounds generally subsuming stone chambers containing collections of bones. Jenni Anderson has kindly permitted use of her illustration of the foundations of a Neolithic mortuary structure which later became a barrow (Fig. 3).

Anderson's drawing interprets Kinnes' description of his Wayland's Smithy excavation in 1975 . The structure was assumed to be a ritual space for the dead. ${ }^{36}$ The lithics forming the small mound at the centre of the

33 National Geographic Data Centre, 'www.Ngdc.Noaa.Gov/Geomagmodels', [Accessed 15 March 2013].

${ }^{34}$ Bradley E. Schaefer, 'Atmospheric Extinction Effects on Stellar Alignments', Archaeoastronomy 10, no. xvii (1986): p. 41.

${ }^{35}$ Stellarium 0.12.0; Starlight, www.Zyntara.com.

${ }^{36}$ I. Kinnes, 'Monumental Function in British Neolithic Burial Practices', World Archaeology 7, no. 1 (1975). 
illustration were the stones found at the heart of the barrow. The barrow would only have come into existence when the stones were covered with earth and even more stones. And it is at this point that a choice is made. The new structure could be round or long. It is of interest to the archaeoastronomer that the form chosen for the Cotswold-Severn barrows was an elongated one which laid an axis across the landscape. As Darvill points out, 'since one essential feature of a long barrow is its linear form, each will naturally have an orientation'. ${ }^{37}$

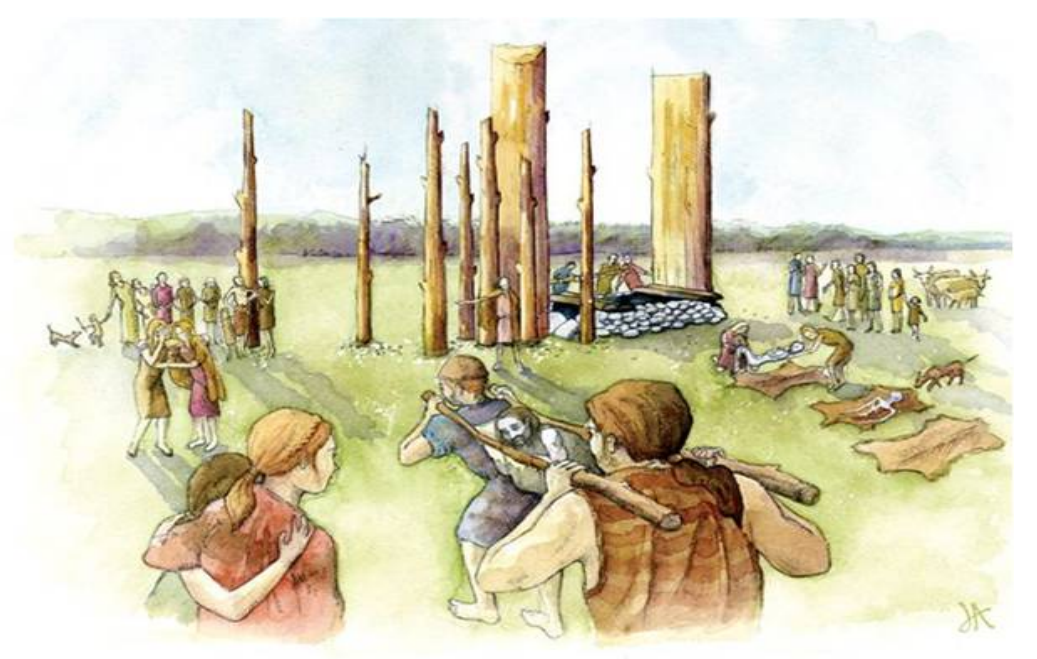

Visualisation of the deposition of human remains within the first mortuary structure at Wayland's Smithy 1, according to lan Kinnes' published theory, 1975. Watercolour \& crayon on watercolour paper, 2009.

Fig. 3. Artist Jenni Anderson's depiction of the primary tomb at Wayland's Smithy.

Where there is an orientation, there may be a deliberate alignment to a celestial horizon event. Certainly this is the case with the Cotswold-Severn long barrows, which offer such a rich resource for investigation of astronomic intent. The aerial photograph below shows Wayland's Smithy today, lying across the centre of a copse (Fig. 4).

\footnotetext{
${ }^{37}$ Darvill, Cotswolds, p. 97.
}

Culture and Cosmos 


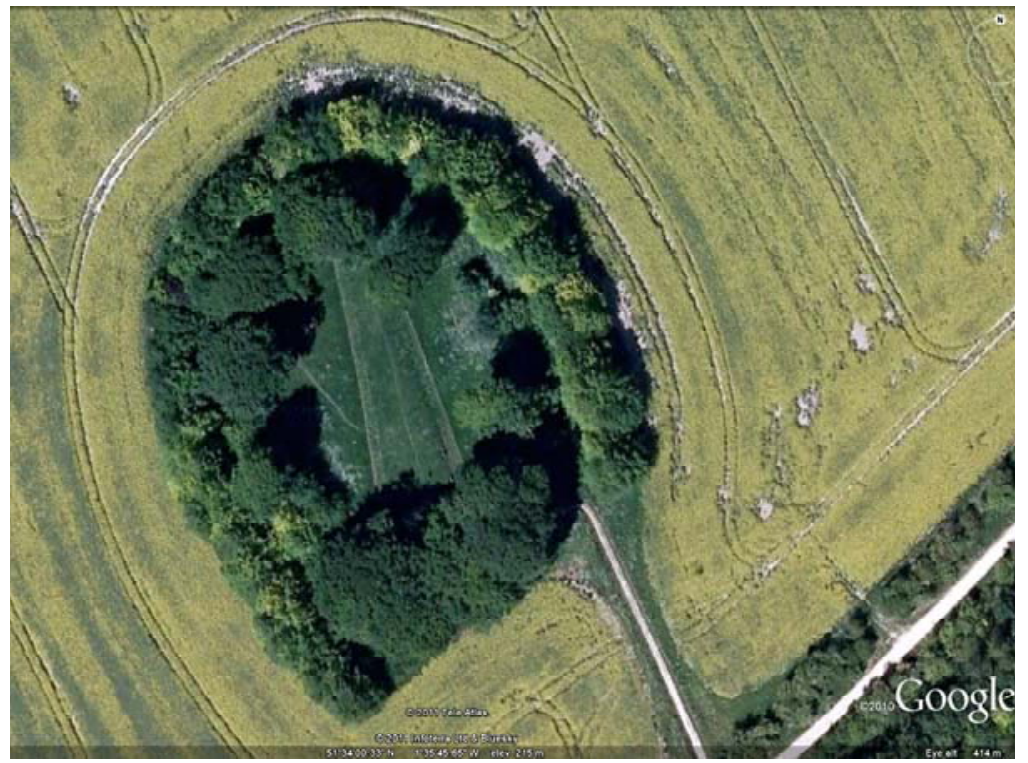

Fig. 4. Wayland's Smithy long barrow. Google earth image.

The mound below is known as the Gatcombe barrow (Fig. 5).

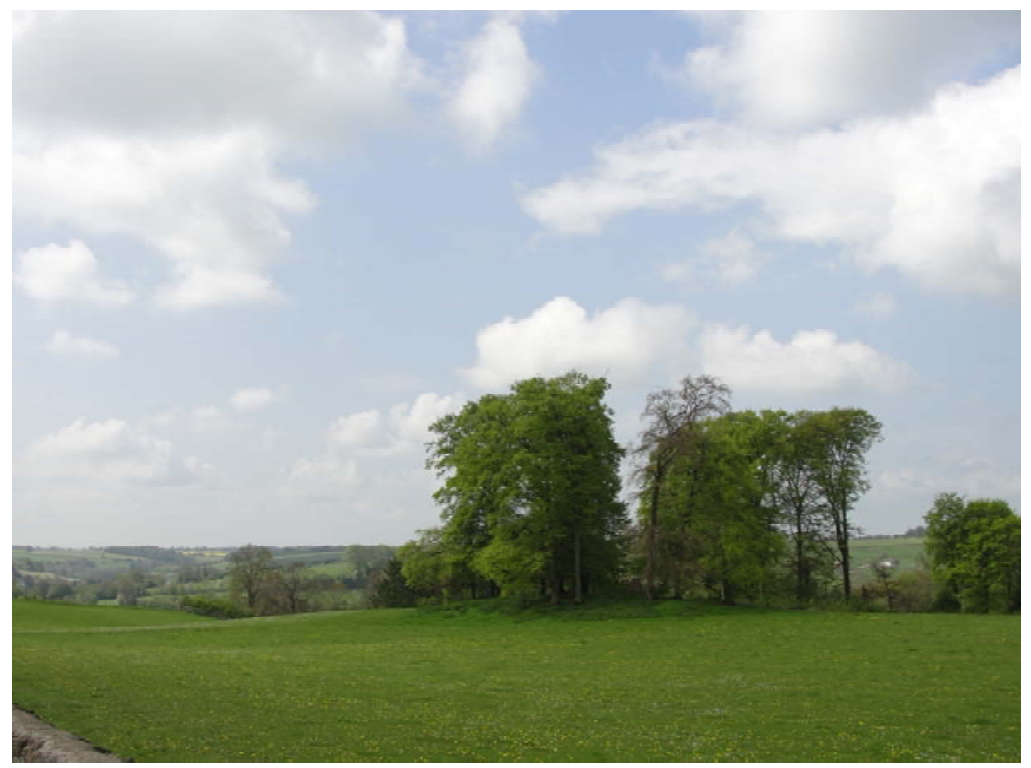

Fig. 5. Gatcombe Long Barrow. Author's photo.

Culture and Cosmos 
One of the best-maintained barrows in the region is Belas Knap, seen below (Fig. 6).

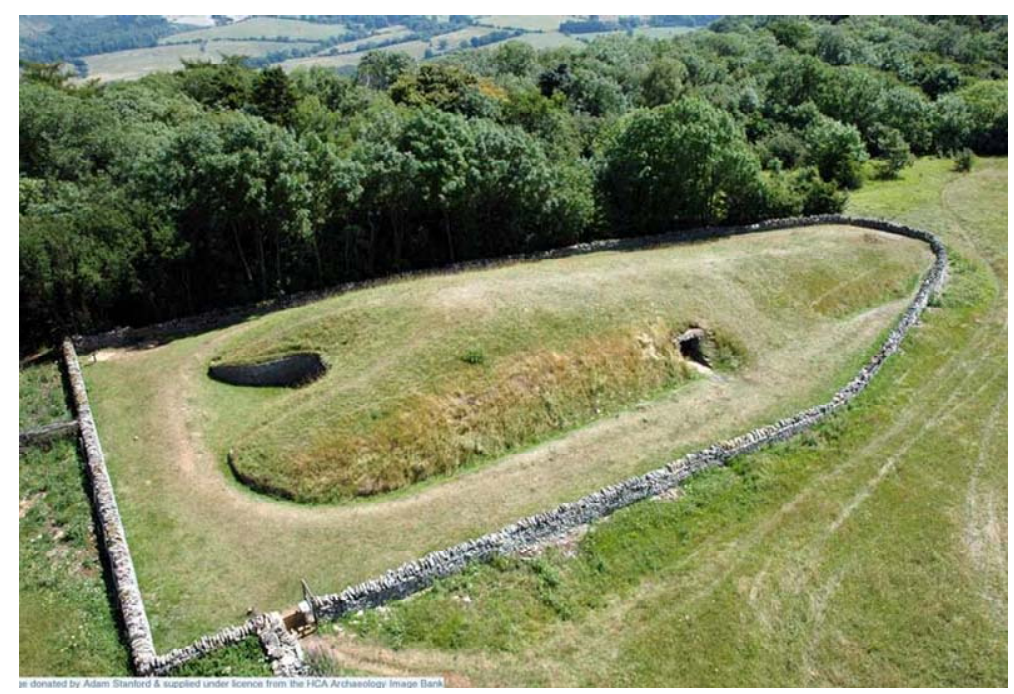

Fig. 6. Belas Knap. Google images.

There is debate about the way barrows should be surveyed. For the purposes of this study I measured the orientation created by the barrow's length. But measurements have been taken across barrows too. North describes the possibility of observing celestial events from just below a barrow, close to its side, 'at right angles' over the mound. ${ }^{38}$ It seems he is inferring that the topmost spine along the barrow afforded an artificial horizon against which the rise or set of sun, moon or stars could be measured. But given the length of the barrows - indeed North mentions Burn Ground, which he describes as being 30 metres long - this creates a relatively wide arc from the observer's point of view. ${ }^{39}$ Celestial observations may have been possible, but few barrows offer evidence of having had poles or standing stones installed along their spines as possible foresights. Given this, it is unclear how any one particular azimuth was judged as more significant than another given the extent of that arc. Thus, whenever surveying a barrow I focus on the orientation created by the length of the mound itself. This was doubly necessary for this particular

\footnotetext{
${ }^{38}$ North, Stonehenge, p. 124.

${ }^{39}$ North, Stonehenge, p. 126.
}

Culture and Cosmos 
survey as the barrows I was researching did not physically exist. Where they were concerned, there was no artificial horizon to look at from a ninety-degree angle to begin with.

In addition, barrows are trapezoidal in shape. If viewed lengthways, their highest point acts as a foresight and their long outline confirms orientation. These two physical characteristics are interdependent and offer an incontrovertible angle towards a clearly identifiable azimuth. These combined features cannot be exploited if the barrow is approached sideways. This appears to imply that barrows provide orientation to only two horizon points, but in fact all my sites revealed orientations at right angles to the primary measurement; however the second set came from architectural features found within the barrows themselves.

The following findings result from combining my fieldwork calculations with diagrams and maps to ascertain azimuths, from which the barrows' declinations were established.

\section{Burn Ground}

Burn Ground was the first barrow in my study. The aerial photograph below is of the barrow itself, or rather what was left of it towards the end of its excavation (Fig. 7).

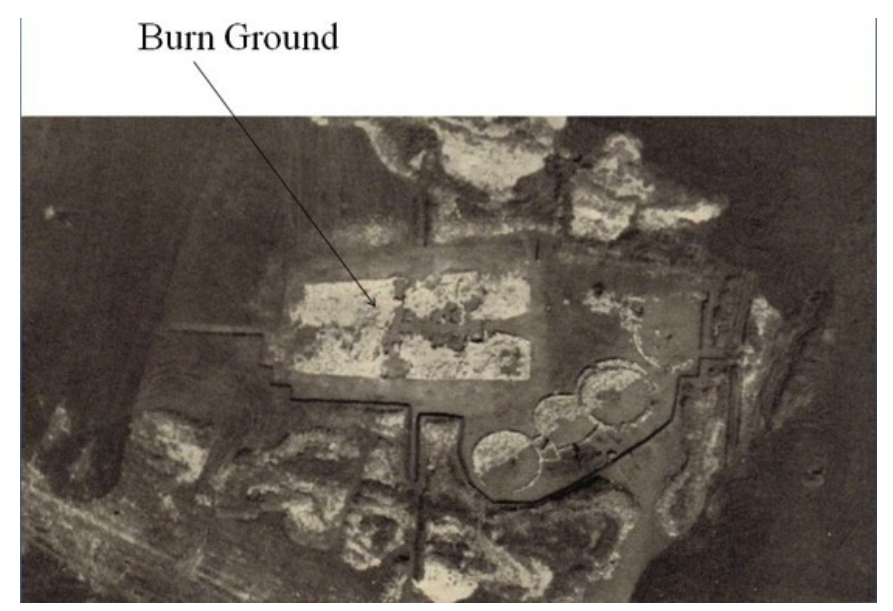

Fig. 7. Excavation site of Burn Ground showing vestigial remains of a long barrow. ${ }^{40}$

${ }^{40}$ Benson, 'Building and Remembrance'. 
Burn Ground was excavated by Grimes during World War II, probably as part of the preparation for turning its mile long field into an airstrip. My survey of this barrow immediately struck a methodological difficulty. Though the excavation itself was documented there were no photographs or maps which illustrated the barrow's setting in its wider landscape. This was one of the points when the hybrid nature of my research came into play.

It was only when I sourced an RAF aerial map from 1947 that I could establish where the barrow lay in relationship to its nearby road (Fig. 8). ${ }^{41}$

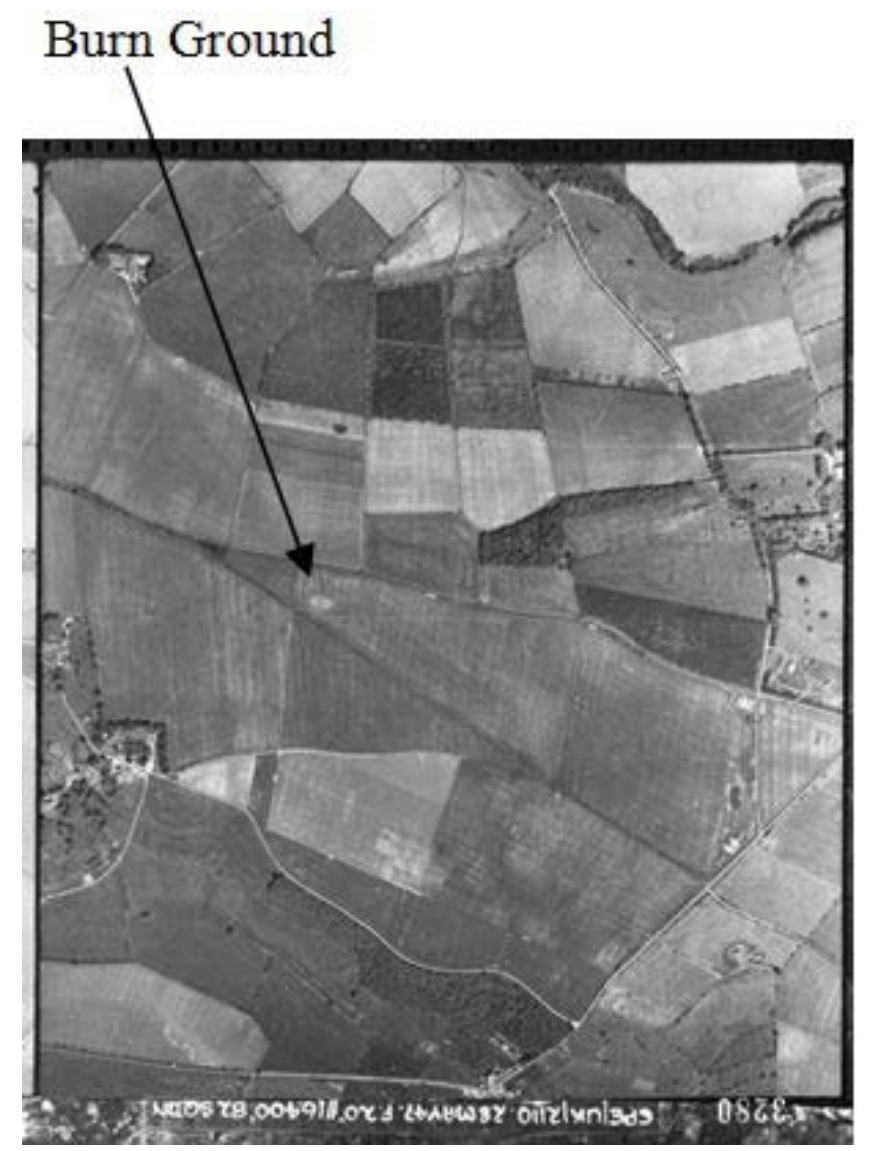

Fig. 8. 1947 RAF aerial map. ${ }^{42}$

\footnotetext{
${ }^{41}$ English Heritage, 'Aerial View of Burn Ground Taken by ' 82 Sqdn', in Serial No: 3280 (Archive, 28 May 1947).

Culture and Cosmos
} 
Turning then to fieldwork measurements, I was able to establish first the azimuth of that road, and from that the azimuth of the barrow (Fig. 9).

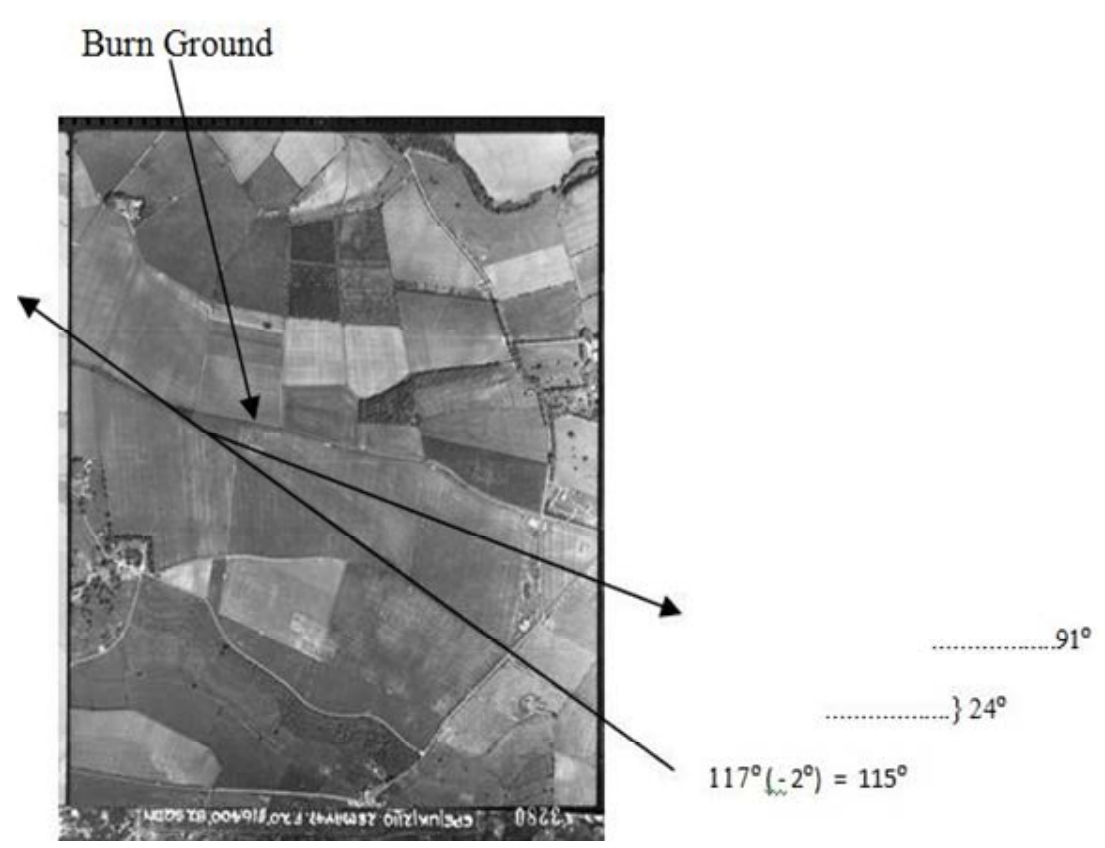

Fig. 9. The azimuth of the A40, which runs along the side of Burn Ground field, and the azimuth of the barrow, in relation to it.

Grimes wrote of Burn Ground that its 'true axis was almost exactly eastwest' and as can be seen, the hybrid methodology that I employed concludes the same. ${ }^{43}$ Burn Ground may have had a single orientation, or possibly two. Zero degrees of declination orients to both the equinox and to what Silva has discovered is one of the probable rise points for eclipsing Autumn Full Moons on a minor lunar standstill. ${ }^{44}$ The fixed stars that the barrow oriented to possibly included Alhena, Procyon, Alphard and Deneb Adige (Fieldwork Findings).

${ }^{42}$ English Heritage, 'Aerial View of Burn Ground'.

${ }^{43}$ W. F. Grimes, 'Excavations on Defence Sites, 1939-1945 1: Mainly NeolithicBronze Age', in Burn Ground, Hampnett, Gloucestershire (London: Her Majesty's Stationery Office, 1960), p. 43.

${ }^{44}$ Fabio Silva, 'Equinoctial Full Moon Models and Non-Gaussianity: Portuguese Dolmens as a Test Case', in Astronomy and Power, eds. Barbara Rappenglueck and Nicholas Campion (British Archaeological Reports, 2011).

Culture and Cosmos 


\section{Ascott-under-Wychwood}

The barrow at Ascott-under-Wychwood was excavated in 1981 (Fig. 10).

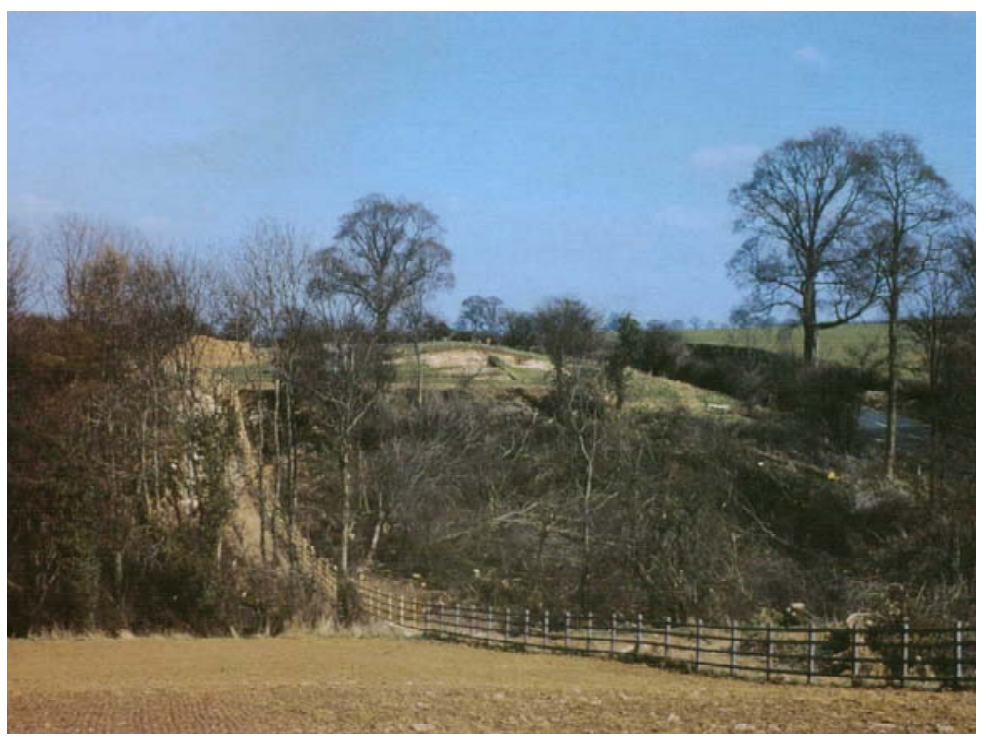

Fig. 10. Excavation site of Ascott-under-Wychwood. $1981 .^{45}$

Its declination was $+9.2 /-8.4^{\circ}$, identified by Silva as one which finds the rising Autumn Full Moon, or the rising eclipsing Autumn Full Moon at minor lunar standstill (Fig 11). ${ }^{46}$ In terms of fixed stars, the barrow also oriented to Alcyone, Deneb Adige, Aldebaran and Vindemiatrix (Fieldwork Findings).

\section{The Hazletons}

Turning to my third site at Hazleton, there were actually two Hazleton barrows, Hazleton North and Hazleton South (Fig. 12). Hazleton North has a declination of $+10^{\circ}$, which again is widely oriented to within a degree or two to the last of Silva's probable rise points for eclipsing Autumn Full Moons on a minor lunar standstill (Fig. 13). ${ }^{47}$ Hazelton South's declination of $-21.5^{\circ} /+23^{\circ}$ is possibly oriented to the rising southern minor lunar

\footnotetext{
${ }^{45}$ Benson, 'Building and Remembrance', p. 381, Plate. 1.1.

${ }^{46}$ Silva, 'Equinoctial Full Moon Models'.

${ }^{47}$ Silva, 'Equinoctial Full Moon Models', Fig. 3, p. 5.

Culture and Cosmos
} 
standstill, which Ruggles suggests stood at $-20^{\circ}$ at this time. ${ }^{48}$ In terms of fixed stars, the Hazletons oriented to Aldebaran, Denebola, Vindemiatrix, Deneb Adige and Sirius.

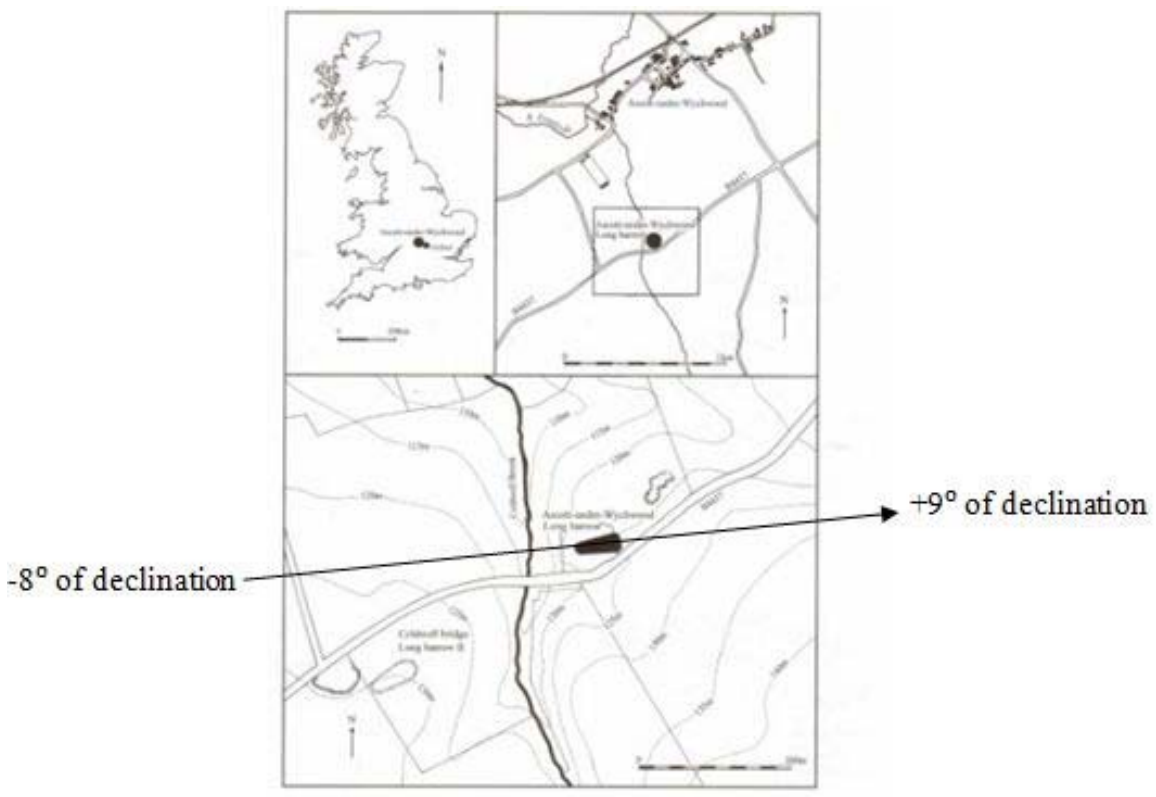

Fig. 11. Declination of barrow at Ascott-under-Wychwood. ${ }^{49}$

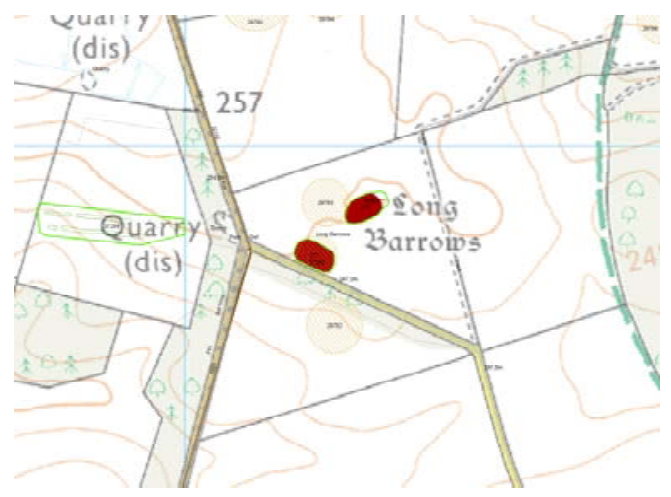

Fig. 12. The Hazleton long barrows.

${ }^{48}$ Ruggles, Prehistoric Astronomy, p. 57.

${ }^{49}$ Benson, Excavations, p. 3. 


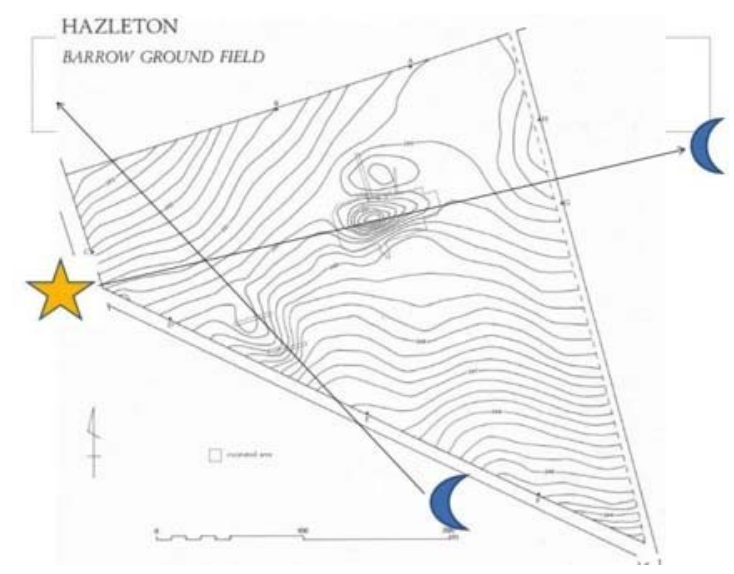

Fig. 13. Hazleton North and South's orientations.

\section{Summary of Barrow Findings}

Burn Ground's possible orientation to the equinox may indicate a solar astronomy applied at this time, though opinion is divided on equinoctial measurements in general. Ruggles argues that the word equinox should be 'eliminated' from the archaeoastronomer's vocabulary, claiming its use displays a 'highly questionable' tacit assumption that it was meaningful in prehistoric times. ${ }^{50}$ In his view, it is an assumption redolent of Westernstyle, abstracted conceptions of space and time. ${ }^{51}$

There are other issues to do with probability too. Though my research question focused on lunar and solar celestial events, my findings began to indicate that stellar orientations should perhaps be considered too. As well as orienting to the sun and moon, it became clear that the barrows made just as persuasive a connection to the stars as well. This may be particularly so, given the difficulties of viewing and recording lunar eclipses and minor lunar standstills, especially the latter given its nineteen year cycle. The annual rise and set of stars may on the other hand be more dependably observable.

When looking at my findings to this point and given the strictures mentioned above, what can be said is that the barrows orient to the sun, moon and stars, but inferring alignment is problematic. Though Ruggles writes that we cannot hope to understand astronomical practice in pre-

\footnotetext{
${ }^{50}$ C. L. N Ruggles, 'Whose Equinox Is It,' Archaeoastronomy 22, no. xxviii (1997): p. 49.

${ }^{51}$ Ruggles, 'Whose Equinox', p. 48.

Culture and Cosmos
} 
historic times without 'beginning to think more seriously' about the people themselves, the information available on the Cotswold landscape is limited. There are no artefacts which indicate that astronomy may have been practiced. My research data represents as much archaeoastronomic evidence as I felt could be justifiably inferred from the sites surveyed. ${ }^{52}$

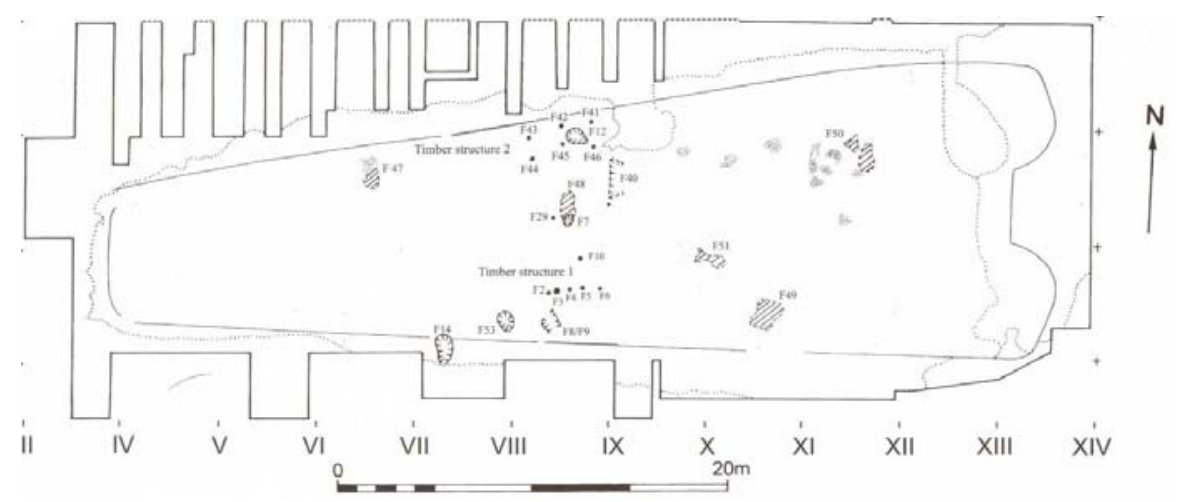

Fig. 14. Ascott-under-Wychwood. Numbered post-holes in pre-barrow context. $^{53}$

This brought my survey's primary line of enquiry to a close. However, the archaeological evidence I came across indicated that an exploration of a deeper time profile may prove of interest. The barrows are Neolithic. But as seen earlier at Wayland's Smithy, and as Darvill explains, many long barrows in the Cotswolds and surrounding areas 'seal' earlier structures. ${ }^{54}$ This was the case at Ascott-under-Wychwood, where a complex pattern of Mesolithic holes were found in the pre-barrow context (Fig. 14).

Lesley McFadyen, an archaeologist at Ascott, was struck by the way the Neolithic barrow 'oriented rather uncannily, in the same direction as the Mesolithic post holes in Timber Structure 1'. ${ }^{55}$ Timber Structure 1 is the lowest, single row of post holes (Fig. 15). Unlike Timber Structure 2 they had no adjacent fire pit. This may indicate that this lower row was not

\footnotetext{
${ }^{52}$ Ruggles, Prehistoric Astronomy, p. 78.

${ }^{53}$ Benson, 'Building and Remembrance', p. 27.

${ }^{54}$ Darvill, Cotswolds, p. 47.

${ }^{55}$ Don Benson and Alasdair Whittle Lesley Mcfadyen, 'The Long Barrow', in Building Memories the Neolithic Cotswold Long Barrow at Ascott-underWychwood, Gloucestershire, ed. Don Benson and Alasdair Whittle (Oxford: Oxbow, 2007), p. 81.
} 
domestic, possibly providing a different function such as establishing an orientation to the horizon.

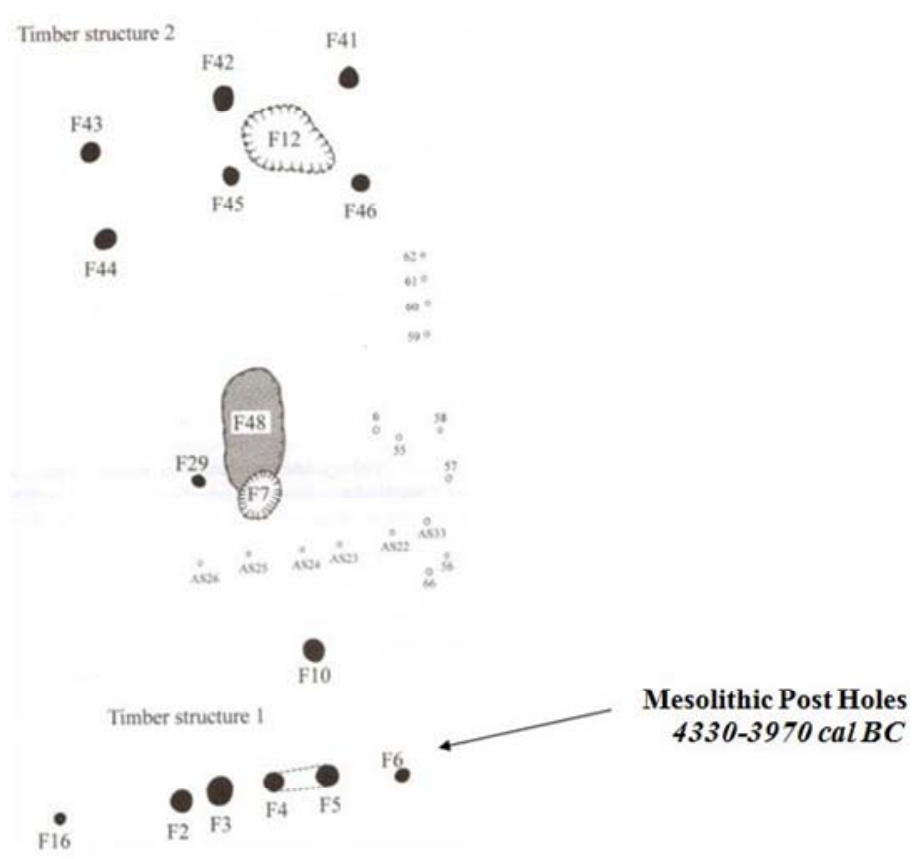

Fig. 15. Mesolithic pre-barrow post holes, one of which contained beech charcoal, subsequently dated. ${ }^{56}$

This uncanny replication of orientation noticed by McFadyen occurred between the Mesolithic post holes and the later row of stake holes created by the Neolithic barrow builders, dated 3760-3700 cal BCE (Fig. 16).

This row of stake holes was the first thing constructed. The line they inscribed on the land established the barrow's fundamental axis, with the final structure subsequently following their angle. This initial marking of the barrow's orientation at its very foundation was typical of the time. North explains the intention behind this process:

The much flimsier lines of stakes found in so many earthen barrows, clearly mark the stages of construction. The conjecture [being] that the stakes were deliberately set in the directions of lines of sight. ${ }^{57}$

\footnotetext{
${ }^{56}$ Benson, 'Building and Remembrance', p. 28

${ }^{57}$ North, Stonehenge, p. 121.

Culture and Cosmos
} 


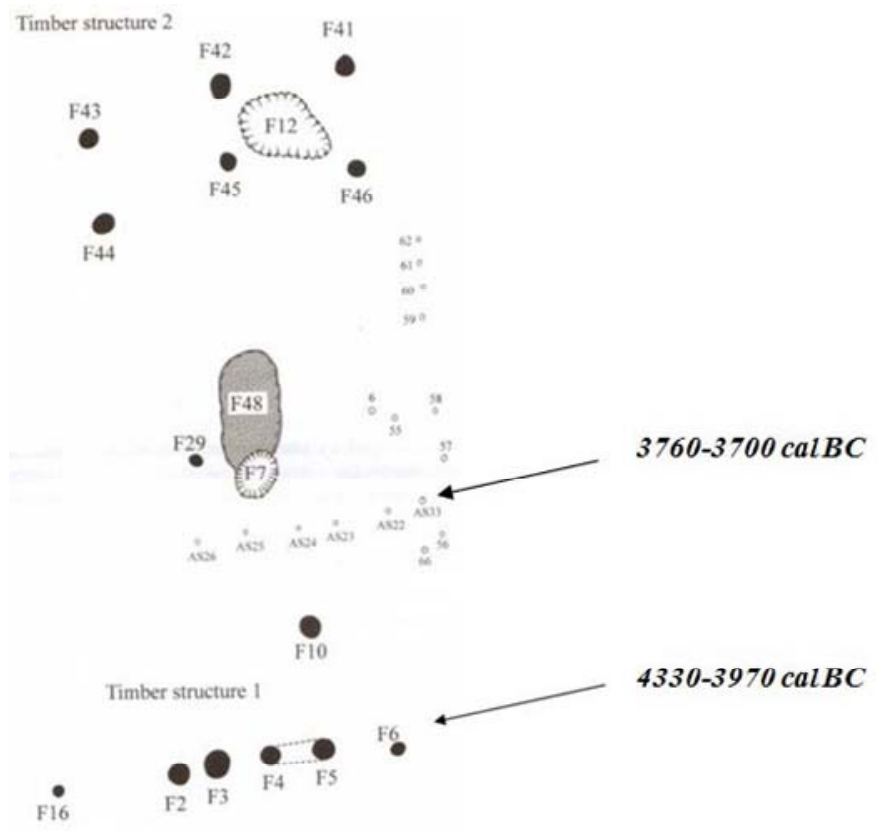

Fig. 16. Mesolithic post holes and Neolithic axial divide ${ }^{58}$

In the case of Ascott-under-Wychwood, as can be seen from the diagram, the orientation of the Neolithic stake holes paralleled the earlier Mesolithic post holes (Fig. 16). Thus anything up to six hundred years after the Mesolithic orientation was established, the Neolithic monument replicated it. As mentioned, the Ascott-under-Wychwood barrow oriented to the rising Autumn Full Moon, as well as the rising eclipsing Autumn Full Moon at minor lunar standstill, and so did the Mesolithic post holes below it (Fig. 17).

${ }^{58}$ Benson, 'Building and Remembrance', p. 28. 


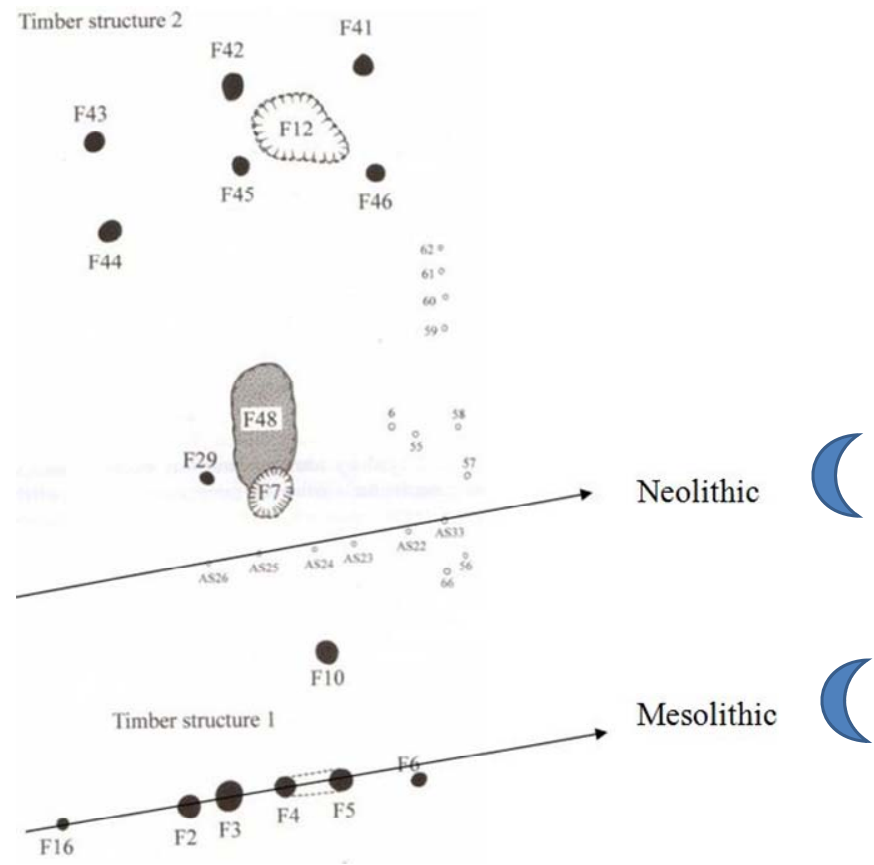

Fig. 17. Replication of orientation across eras. ${ }^{59}$

\section{Mesolithic Landscape at Stonehenge}

Once this possible astronomic continuity across the Mesolithic/Neolithic transition had been identified, it led to me a second line of enquiry. Though my original research focused on the Neolithic of the north Cotswolds, given that barrows often 'seal' earlier Mesolithic sites I felt that such continuities as clearly applied at Ascott-under-Wychwood may have similarly applied at Stonehenge. ${ }^{60}$ The material record at Stonehenge covers a wide time range and since that record is dated it is possible to establish a similar diachronic profile at Stonehenge as the one I applied to the north Cotswold barrows. The evidence I was looking for would need to be pre-sarsen stone circle, and this is found in the form of three Mesolithic post holes which are currently covered by tarmac in the Stonehenge car park (Fig. 18). Figure 19 shows the location of posts A / B / C.

\footnotetext{
${ }^{59}$ Benson, 'Building and Remembrance', p. 28.

${ }^{60}$ Darvill, Cotswolds, p. 47.

Culture and Cosmos
} 


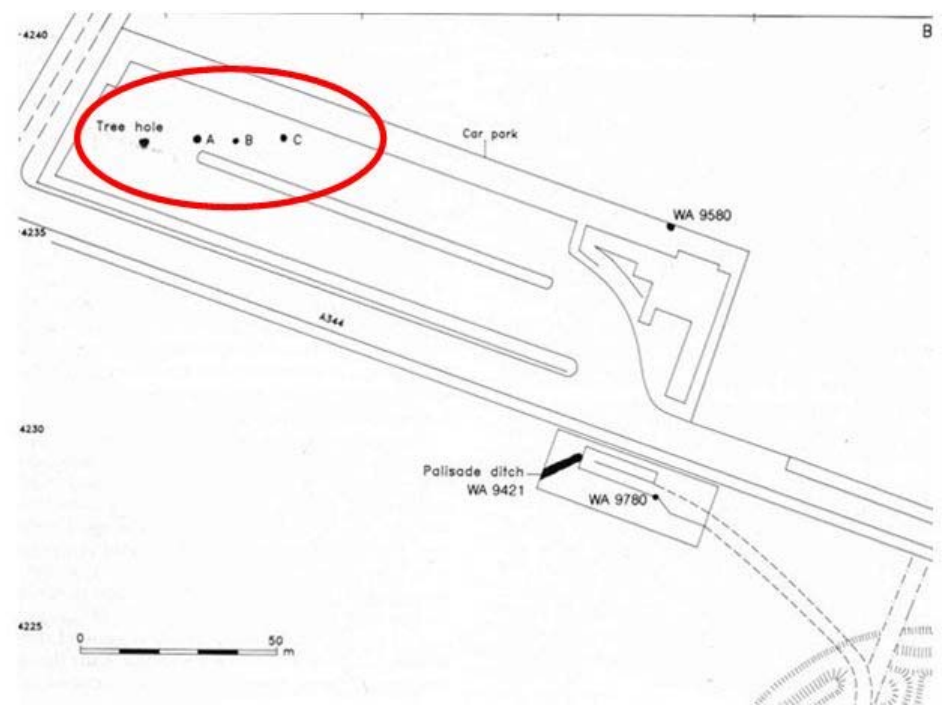

Fig. 18. Diagram of car park showing post holes A / B / C. ${ }^{61}$

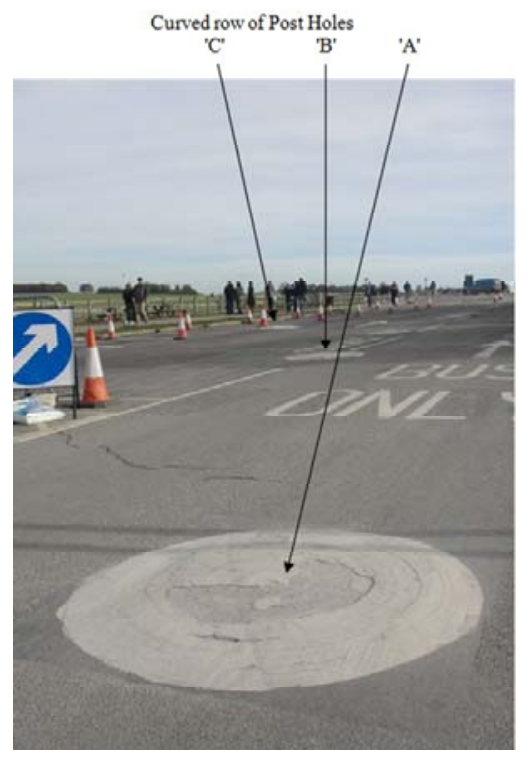

Fig. 19. Mesolithic car park post holes. Post hole $C$ was undated so was not included in this discussion.

${ }^{61}$ Rosamund M. J. Cleal, Stonhenge in Its Landscape (London: English Heritage, 1995), p. 42.

Culture and Cosmos 
A site survey revealed that the orientation created by posts A and B had a declination of $-0^{\circ} \% 1^{\circ}$ (Fig. 20).

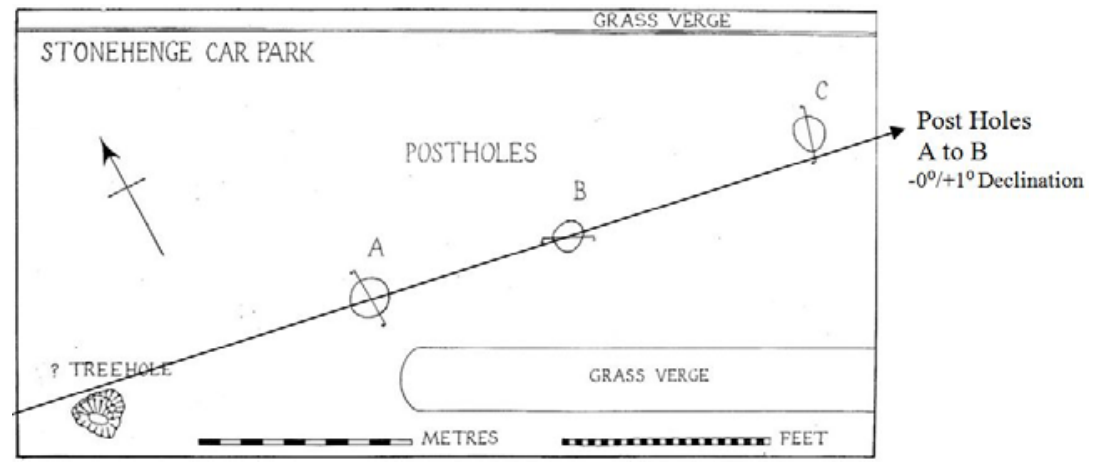

Fig. 20. Post Holes A to B. Declination $-0^{\%} / 1^{\circ} .^{62}$

Loveday's survey of the orientation created by posts A and B also arrived at a measurement of zero degrees of declination. As at Burn Ground, this may indicate an alignment to both lunar and solar equinoctial horizon events. ${ }^{63}$ In terms of the fixed stars, Pollux rose at zero degrees of declination at this time ${ }^{64}$ When considering installation of the posts and their sequence, I suggest post A to B is actually the second orientation created at this location. Cleal dates Post B sometime between 7480-6590 cal BCE, but she dates Post A as earlier, sometime between 8820-7730 cal BCE. ${ }^{65}$ Thus it is possible that Post A was joined with the tree (Fig. 21) to create the first orientation.

As my fieldwork established a primary azimuth between posts A and B, it was possible to gauge this second orientation of the tree and post A in relation to the first, and that process gave a declination of $+5 \%-4^{\circ}$. If intended, this was an alignment to the rising Autumn Full Moon and the rising eclipsing Autumn Full Moon at minor lunar standstill. ${ }^{66}$ Should this be the case, it suggests that the first orientation established on this Mesolithic hillside was a lunar one, which again supports Sims' theory. ${ }^{67}$

\footnotetext{
${ }^{62}$ Roy Loveday, 'The Greater Stonehenge Cursus-the Long View', Proceedings of the Prehistoric Society 78 (2012): p. 344.

${ }^{63}$ Loveday, 'The Greater Stonehenge', p. 345.

${ }^{64}$ Stellarium 0.12.0; Silva, 'Equinoctial Full Moon Models'.

${ }^{65}$ Cleal, Stonehenge / Landscape, p. 43.

${ }^{66}$ Silva, 'Equinoctial Full Moon Models'.

${ }^{67}$ Sims, ‘Solarization', p. 1.

Culture and Cosmos
} 
Car park Tree to Post A

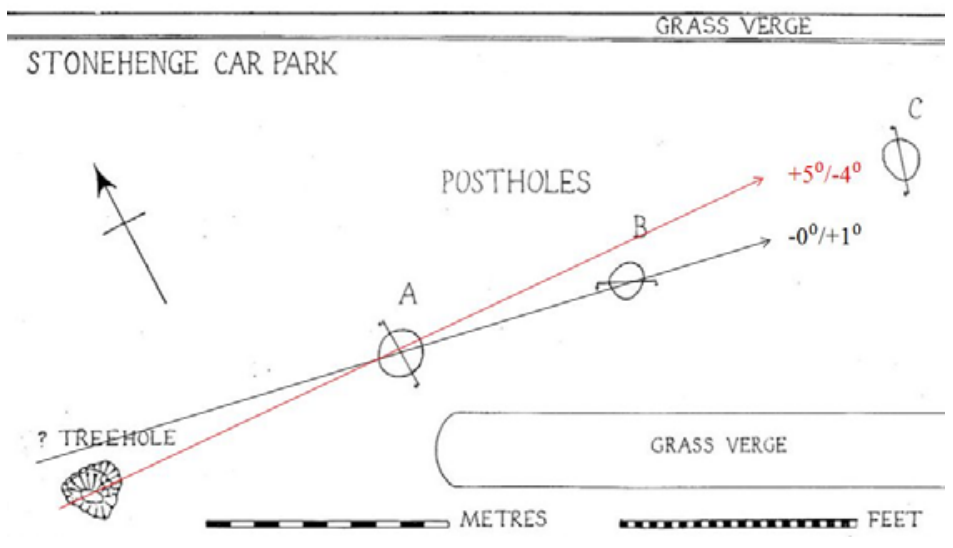

Fig. 21. The Tree to Post A's declination is $+5 \% / 4^{\circ}{ }^{68}$

However the arrival of a possible equinoctial orientation shown by the second orientation from Post A to B may indicate that a solar astronomy joined the original lunar one. Given the different dates that apply to the post holes this may have occurred without pause or over a period of up to two thousand years, however both orientations were established in the Mesolithic (Fig. 22).

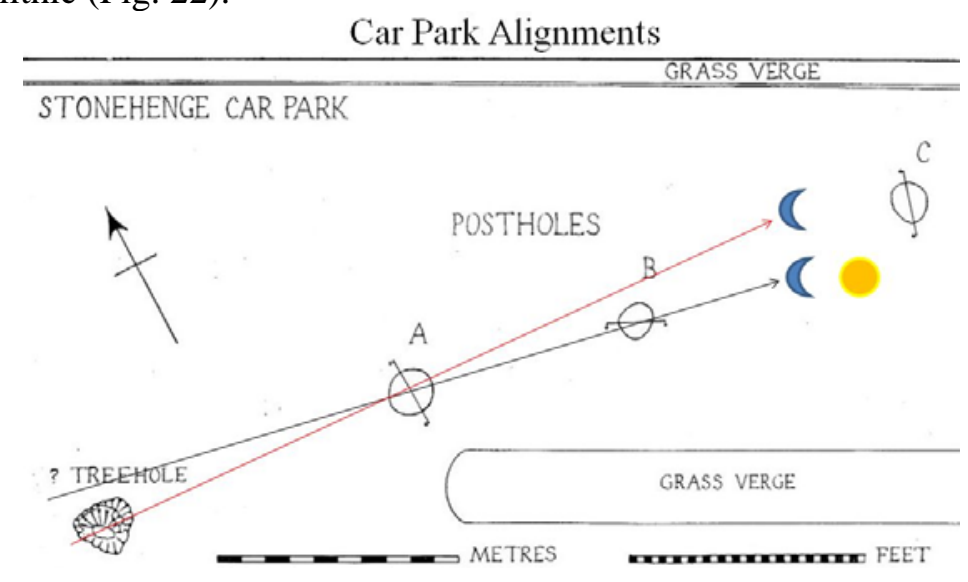

Fig. 22. Sun/Moon orientations from the car park. First orientation. Tree to Post A. Lunar. Post A dated 8820-7730 BCE; second orientation. Post A to B. Soli/lunar. Post B dated 7480-6590 BCE. ${ }^{69}$

${ }^{68}$ Loveday, 'The Greater Stonehenge', p. 344.

Culture and Cosmos 


\section{Summary}

In summary, the aim of my survey was to consider the question, 'Does the archaeoastronomic record of the Cotswold-Severn region reflect evidence of a transition from lunar to solar alignment?' Sims' 'solarization' theory was used as the basis of this study. ${ }^{70} \mathrm{He}$ argues that in central, southwestern England there was an abrogation from a predominantly lunar to a solar astronomy. ${ }^{71}$ Stonehenge was designed, he suggests, in order to engineer this transition. ${ }^{72}$ According to Sims, the process of 'solarization' occurred during the sarsen phase of Stonehenge, which dates to around '2413 BCE' ${ }^{73}$ When arguing for this cultural and essentially calendrical shift Sims recommends there be a reinvestigation of evidence further afield than Stonehenge 'for earlier versions of the same complex'. ${ }^{74}$ My research has attempted that reinvestigation, focusing on the archaeoastronomic properties of Cotswold-Severn earthen barrows.

The methodology I used to explore these burial chambers was qualitative and hybrid, including fieldwork and in depth analysis of archaeological reports. One of the fundamental aims of my research was to establish a dating sequence in order to contextualise and compare orientations and thus possible alignments. The barrows I chose ranged in date from the very end of the fifth millennium to around 3600 BCE. However, the unexpected emergence of Mesolithic post-hole measurements discovered in pre-barrow contexts prompted me to deepen my time frame. I decided to include a survey of the eighth and ninth millennium post holes in the car park at Stonehenge. ${ }^{75}$ If orientation from that earliest time did emerge, it could then be contrasted with evidence from the Neolithic, my latest barrow being dated to '3710-3655 cal $B C E,{ }^{76}$ Thus I created a diachronic profile of one small part of the material record across the Mesolithic to Neolithic transition in central southern England. This profile has allowed me to explore the possible astronomies of those who inhabited this region at this time. A number of issues arose during this survey, some to do with the research process itself and others to do with my findings.

${ }^{69}$ Cleal, Stonehenge / Landscape. p. 43.

${ }^{70}$ Sims, 'Solarization', p. 3.

${ }^{71}$ Sims, 'Solarization', p. 14.

${ }^{72}$ Sims, 'Solarization', p. 3.

${ }^{73}$ Cleal, Stonehenge / Landscape, p. 231.

${ }^{74}$ Sims, 'Solarization', p. 14.

${ }^{75}$ Cleal, Stonehenge / Landscape, p. 43.

${ }^{76}$ Meadows, Barclay, and Bayliss, 'Dating of the Hazleton Long Cairn’, p. 54.

Culture and Cosmos 


\section{The Research Process}

Turning first to the hybrid methodology used in this study, it may be of some use to consider its feasibility. The combined use of fieldwork and archaeological report was in direct response to the fragile, ancient material record under investigation. But even though best endeavours were used, it is possible that some calculations are more dependable than others. For instance my measurement for Ascott-under-Wychwood eventuated in an azimuth that at $5^{\circ}$, differed two degrees from that of the report. As Benson, who wrote the report, was still alive I both emailed and telephoned him. ${ }^{77}$ When questioned about his compass measurement he verbally confirmed and also wrote 'I am confident about the 7 degrees north of east' ${ }^{78}$ I could only source one rough illustration of the Ascott barrow in relation to its nearby road and as that was perhaps too blunt a tool to rely on, thus I decided to accept Benson's judgement as final (Fig. 23).

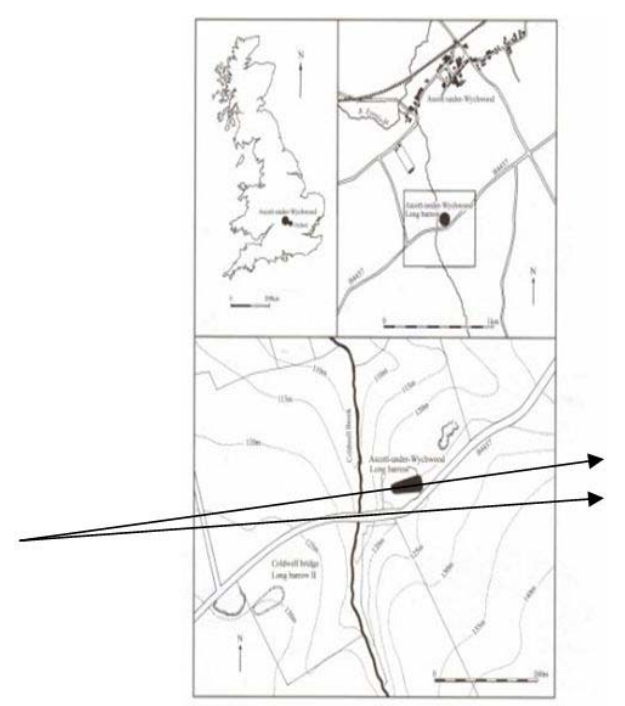

Fig. 23. Lower Map, roughly drawn, showing barrow in relation to nearby road. ${ }^{79}$

At Hazleton North on the other hand, the diagrams were finely drawn and I used them with confidence. Combining Savill's illustrations with my own

\footnotetext{
77 Don Benson, 11 November 2012.

${ }^{78}$ Benson, 4 March 2013.

${ }^{79}$ Benson, Excavations, p. 3.
} 
compass measurement of the nearby road I arrived at an azimuth from magnetic north of $79^{\circ}$ (Fig. 24).

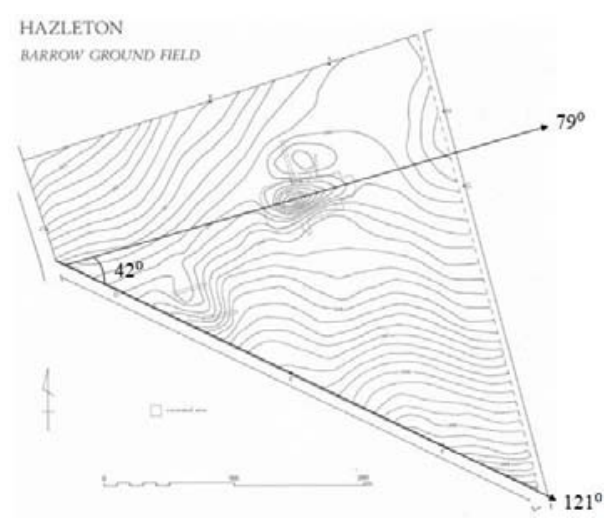

Fig. 24. Hazleton North barrow's azimuth of $79^{\circ}$ from magnetic north, in relation to adjacent road. Contour survey: contours in metres above OD at 0.25 vertical intervals. ${ }^{80}$

Magnetic North stood at $-1.9^{\circ}$ on 29th April 2013, the day of my fieldwork so Hazleton North's azimuth, when recalculated, stood at $77^{\circ}$. I subsequently discovered this corresponded with Savill's measurement. He too estimated that the barrow stood at $77^{\circ} \cdot{ }^{81}$ However, he did not specify which north he was referring to so I emailed him in order to check and had to accept his reply:

I'm afraid my memory is not up to helping... [One] thing I would add is that the text does say east of north rather than east of magnetic north, but that is perhaps clutching at straws. ${ }^{82}$

So Hazleton North and Ascott-under-Wychwood's measurements were arrived at using the best information a hybrid methodology could source, but it is clear when that methodology's limit has been reached.

Measurements for the other two sites may perhaps be viewed more confidently. Grimes noted that Burn Ground's 'true axis was almost

${ }^{80}$ Alan Saville, 'Hazleton North, Gloucestershire, 1979-82 the Excavation of a Neolithic Long Cairn of the Cotswold Severn Group', in Archaeological Report no 13, ed. Elizabeth Hall and John Hoyle (English Heritage, 1990), p. 5.

${ }^{81}$ Saville, 'Hazleton North', p. 34.

${ }^{82}$ A Saville, 2014, January, Email.

Culture and Cosmos 
exactly east-west' and indeed my fieldwork and map usage suggested the barrow had a declination of $-0.6^{\circ} /+0.6^{\circ}$. $^{83}$ The same process allowed me to gauge azimuths for the post holes at Stonehenge. My calculation of $91^{\circ}$ corresponded to Loveday's exactly and this led me to more confidently use a diagram to estimate the second orientation at that site. ${ }^{84}$ It may be best to assume this level of congruency will not always occur but considering the process overall, hybrid methodologies may find a use with when sensitively applied to appropriate projects.

\section{Research Findings}

Returning to the question at the heart of my survey, which asked whether a solar astronomy superseded a lunar one in this region, my findings seem to suggest an attachment to lunar astronomy did apply during the Mesolithic and this continued into the early Neolithic. Sims claims there existed 'an ancient cosmology which in its astronomical aspects had focused on the moon', and indeed, the earliest orientation discovered in my survey was the lunar one on the Mesolithic Stonehenge hillside created by the Tree to Post $\mathrm{A}^{85}$ The last lunar orientation was found at my 'youngest' site, Neolithic Hazleton North. This supports Sims theory that a lunar astronomy possibly applied in this region pre-sarsen Stonehenge. However, the emergence of a second orientation on the hillside at Stonehenge, dated to the Mesolithic and this time to zero degrees of declination raises the possibility of solar equinoctial orientations joining lunar ones as early as the eighth millennium BCE. This 'solar' measurement joins with Neolithic Burn Ground, and Hazleton South's equinoctial orientations, respectively. Sims argues it was 'the Neolithic and Early Bronze Age introduction of solar symbolism [that] was to modify and transcend earlier engagement with the moon' ${ }^{86}$ But as the Mesolithic car park post holes clearly predate 'solarizing' mid-Neolithic Stonehenge, it is possible that an appreciation of a solar horizon event was in place before both those eras. ${ }^{87}$

It is, however, necessary to exercise caution when assessing the equinoctial point. As Silva points out, zero degrees of declination can have lunar as well as solar qualities. ${ }^{88}$ It is not possible to assume one particular

\footnotetext{
${ }^{83}$ Grimes, 'Excavations’, p. 43.

${ }^{84}$ Loveday, 'Greater Stonehenge’, p. 345.

${ }^{85}$ Sims, 'Solarization', p. 3.

${ }^{86}$ Sims, 'Solarization'.

${ }^{87}$ Cleal, Stonehenge / Landscape, p. 43.

${ }^{88}$ Silva, 'Equinoctial Full Moon Models'.
} 
luminary was preferenced at this rise and set point. Given its bimodality, zero degrees remains a declination resistant to definitive interpretation. Separate to the above, another aspect to this declination is that given the sun's speed along this part of the horizon, it is difficult to measure the exact equinoctial point. However, one of my barrows may have been specifically sited to address this problem. Burn Ground was an anomaly in that not only was it the only barrow I surveyed which had zero degrees of declination, it was also the only one located on a completely flat landscape (Figs. 25 and 26).

This choice of site was atypical given the generally rolling and hilly Cotswold landscape. It may have been that this particular barrow's zero degree altitude, local horizon was deliberately chosen in order to facilitate the most precise equinoctial measurement possible.

One aspect of my research findings which would bear closer study is the use of the word lunar. The 'lunar' orientations which possibly emerge in these findings are to rising Autumn full moon eclipses at Minor Standstill, or a rising Autumn Full Moon. But this phraseology infers an emphasis on the moon, when the sun is just as integral to these events. Full moons and lunar eclipses are simply the culmination of a complex and continuous soli/luni syzygy.

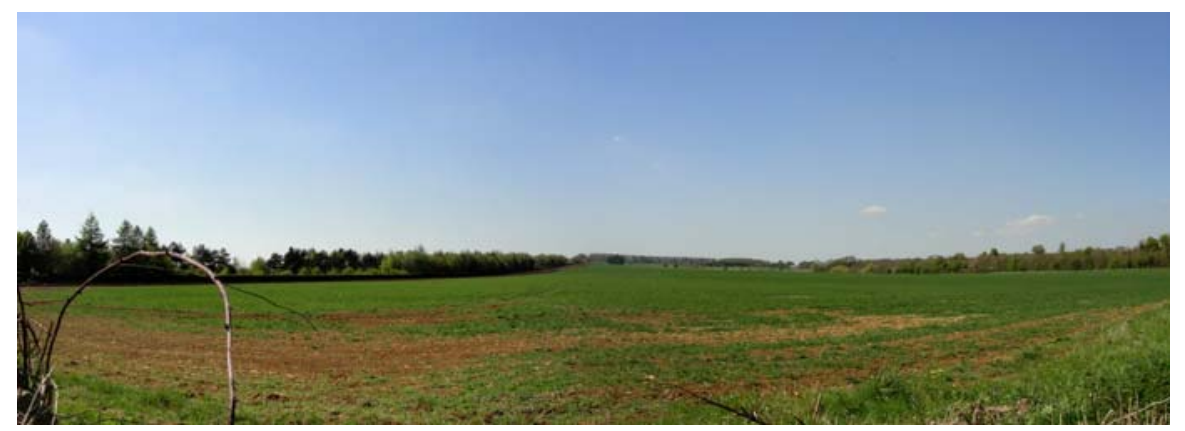

Fig. 25. Burn Ground $180^{\circ}$ Panorama. The entire length of the field taken from the south-east. Author's photo.

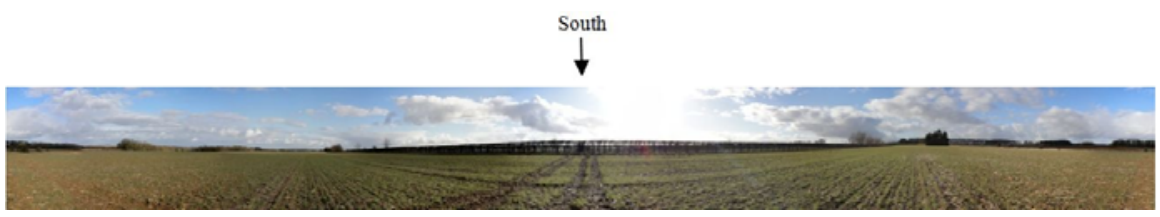

Fig. 26. Burn Ground $360^{\circ}$ Photographic Panorama. Author's photo.

Culture and Cosmos 
Taking the rising Autumn Full Moon first, Silva argues that combined with the Spring Full Moon, it is one of only two annual celestial horizon events that sees both sun and moon visibly oppose each other across the horizon. ${ }^{89}$ As the moon rises at $+4^{\circ}$ of declination it directly opposes the setting sun at $-4^{0}$ of declination and an 'equinoctial axis' is formed. ${ }^{90}$ It is possible that this rare celestial event may have been meaningful in and of itself, but whatever its symbolic function, it involved both luminaries.

Turning to the second 'lunar' orientation which emerged from my study, that was to the rising Autumn Full Moon eclipse at minor standstill. These are eclipses during which the Moon is seen to turn red. ${ }^{91}$ They unfold over a number of hours, the actual totality lasting anything up to 72 minutes. As Silva points out, the darkening of a bright Autumn Full Moon at minor standstill is visually arresting. ${ }^{92}$ But of note is that these too are equinoctial full moons, they occur just after the sun and the moon are seen to cross over the equinoctial point as they travel in opposite directions along the horizon. C. Marciano Da Silva explains how the horizon relationship between the luminaries is clearly visible at this time. 'One way or the other,' he writes of this full moon, '(it) would be the first full moon past the sun. ${ }^{93}$ Thus as with the non-standstill Autumn Full Moon, both luminaries figure.

So on closer inspection it may be inferred that the sun is as implicated in these 'lunar' events as the moon. In both instances the lunar component is indivisible from the solar. Certainly there is no way of establishing which luminary was linguistically prioritised in prehistory. The 'lunar' horizon events possibly revealed in my research happen within days of the autumn equinox, a term currently used to define what is considered a solar calendar moment. But when it comes to describing Equinoctial Full Moons, Silva points out this is, 'the time the sun and moon actually change positions in the sky,' and then he adds, 'In fact, it is possible that EFMs (Equinoctial Full Moons) are the ethnographic definition of equinox' ${ }^{94}$ If

89 Fabio Silva, 'Equinoctial Full Moons and Solstitial Crescent Moons: An Empirical Luni-Solar Division of the Year?', in Ninevah to Chaco: Calendars through Time (Pagosa Springs, 2011).

${ }^{90}$ Silva, 'Equinoctial Full Moons and Solstitial Crescent Moons: An Empirical Luni-Solar Division of the Year?', Slide 4.

${ }^{91}$ Fabio Silva, 2013, Email.

${ }^{92}$ Silva, 'Equinoctial Full Moon Models’, p. 4.

${ }^{93}$ Da Silva, 'Spring Full Moon', p. 476.

${ }^{94}$ Silva, 'Equinoctial Full Moon Models', p. 5. 
this was the case, it suggests an appreciation and experience of sun and moon as indivisible in terms of their relationship each to the other.

Turning to another aspect of my findings and separate to the luni/solar discussion above, though Sims makes no mention of the stars, unexpected but repeated stellar orientation emerged throughout my survey. These were to the very brightest stars on the east, west and northern horizons and suggest that if astronomy was practised at this time, it contained a stellar component. If this was the case there may have been created what Brady terms a 'cosmic and cultural knot'. ${ }^{95}$ This supposes a complex relationship with sun, moon and stellar sky lore for navigational, calendrical and ritual purposes.

Lastly, there may be an ethnographic aspect to my findings, given their seasonal emphasis. There was a predominance of orientations to celestial events which occur around the equinoxes. Setting aside observational and record keeping problems, this may indicate that during the Mesolithic to Neolithic transition, trade and ritual gatherings occurred at these times of year. The specific events include a single orientation to an Autumn Full Moon, which was the earliest one found at ninth millennium Stonehenge and subsequent to that all further orientations were to Autumn Full Moon eclipses at minor standstill. This may possibly indicate an astronomy which evolved over time into one that appreciated both eclipses and longer cycles.

In conclusion, my survey aimed to consider the question, 'Does the archaeoastronomic record of the Cotswold-Severn region reflect evidence of a transition from lunar to solar alignment?' Sims' 'solarization' theory was chosen as the originating research for this study, wherein he argued that in central, south-western England there was an abrogation from a predominantly lunar to a solar astronomy. ${ }^{96}$ Stonehenge was, he suggests, designed in order to engineer this transition. ${ }^{97}$ This position appears to assume a 'lunar' astronomy prevailed pre sarsen Stonehenge, but given the range of orientations which emerge from my survey to possibly the sun, the moon and the stars, it may be possible that a more varied appreciation of the sky existed in those earliest of times.

\footnotetext{
${ }^{95}$ Brady, 'Star Paths', p. 4.

${ }^{96}$ Sims, 'Solarization', pp. 3, 14.

${ }^{97}$ Sims, ‘Solarization', p. 3.

Culture and Cosmos
} 